\title{
The Effect of Cold Rolling on the Creep Behavior of Udimet 188
}

\author{
D. Palit and C.J. Boehlert
}

Department of Chemical Engineering and Materials Science, Michigan State University, East Lansing, MI 48824

Udimet alloy 188, also known as Haynes 188 alloy, is a cobalt-nickel-chromium-tungsten alloy with good creep strength and oxidation resistance up to $1093^{\circ} \mathrm{C}$. The high chromium content along with the presence of a small amount of lanthanum produces an extremely corrosion resistant scale. Udimet alloy 188 has good fabricability, tensile ductility, and weldability. It has useful applications in gas turbines, combustors, flame holders, liners, and transition ducts [1].

The alloy was subjected to thermo-mechanical processing in attempt to enhance its mechanical properties. In particular, it was cold rolled to either $10 \%, 25 \%$, or $35 \%$ deformation followed by a solution treatment at $1191{ }^{\circ} \mathrm{C}$ for one hour followed by air cooling. This sequence was repeated four times and the resultant microstructure was characterized using Electron Backscattered Diffraction (EBSD). The fraction of high angle boundaries, low angle boundaries, coincident site lattice boundaries were measured as a function of cold rolling deformation. In addition, the effect of cold rolling on the high-temperature $\left(650-815^{\circ} \mathrm{C}\right)$ creep behavior was evaluated. Conventional lever-arm creep experiments, performed in air, as well as novel in-situ experiments, performed inside an SEM chamber, were used to evaluate the effect of cold rolling deformation on the creep behavior.

Figure 1a illustrates a backscattered electron (BSE) SEM micrograph of a 10\% cold rolled sample prior to creep testing. The light-phase precipitates were evenly distributed. The grain boundaries were intact and no cracks are visible. Based on the minimum creep strain rate versus applied stress behavior, Figure 1b, the 35\% cold rolled condition appeared to have a slightly lower creep resistance than the other conditions. Based on the measured exponent, dislocation creep was the suggested creep mechanisms over the entire applied stress range (100-225MPa).

Figure 2a illustrates a BSE SEM micrograph of a 25\% cold rolled sample taken during an in-situ creep experiment at $650^{\circ} \mathrm{C}$ and $350 \mathrm{MPa}$ load. Intergranular cracking was exhibited throughout the sample. The cracks propagated both perpendicular and parallel to the loading direction. Intergranular cracking was exhibited for each of the cold rolled conditions indicating that this alloy is susceptible to deformation at the grain boundaries. Figure $2 \mathrm{~b}$ represents the EBSD map of another $25 \%$ cold rolled sample after subjecting it to an in-situ creep deformation experiment. The misorientation angles were measured for over twenty grain boundaries and each boundary which exhibited cracking was found to be a random high-angle grain boundary. No cracking was observed across twin $(\Sigma 3)$ boundaries, which ranged in fraction from $10-40 \%$ of the total grain boundary fraction. This implies that twin boundaries may be less susceptible to grain boundary cracking than random high-angle boundaries during creep deformation of this alloy. As a systematic change in the twin boundary fraction was not observed with the thermomechanical processing method used in this study, it remains an open question how to grain boundary engineer [2] this alloy to a majority of special boundary fractions. This will be the target of future work. 

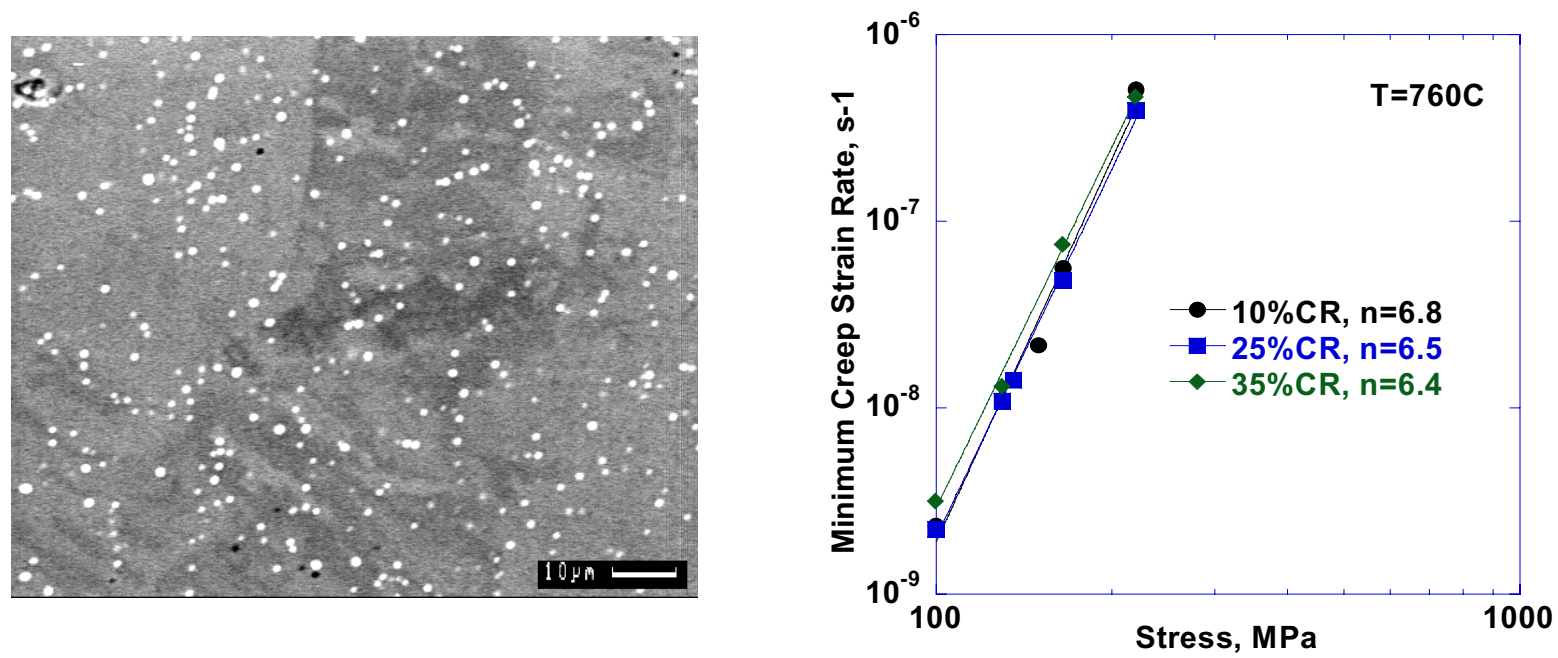

FIG. 1. (a) BSE SEM Micrograph of a 10\% cold rolled sample in pre-test condition. (b) Minimum creep rate versus applied stress for the three cold rolled conditions.
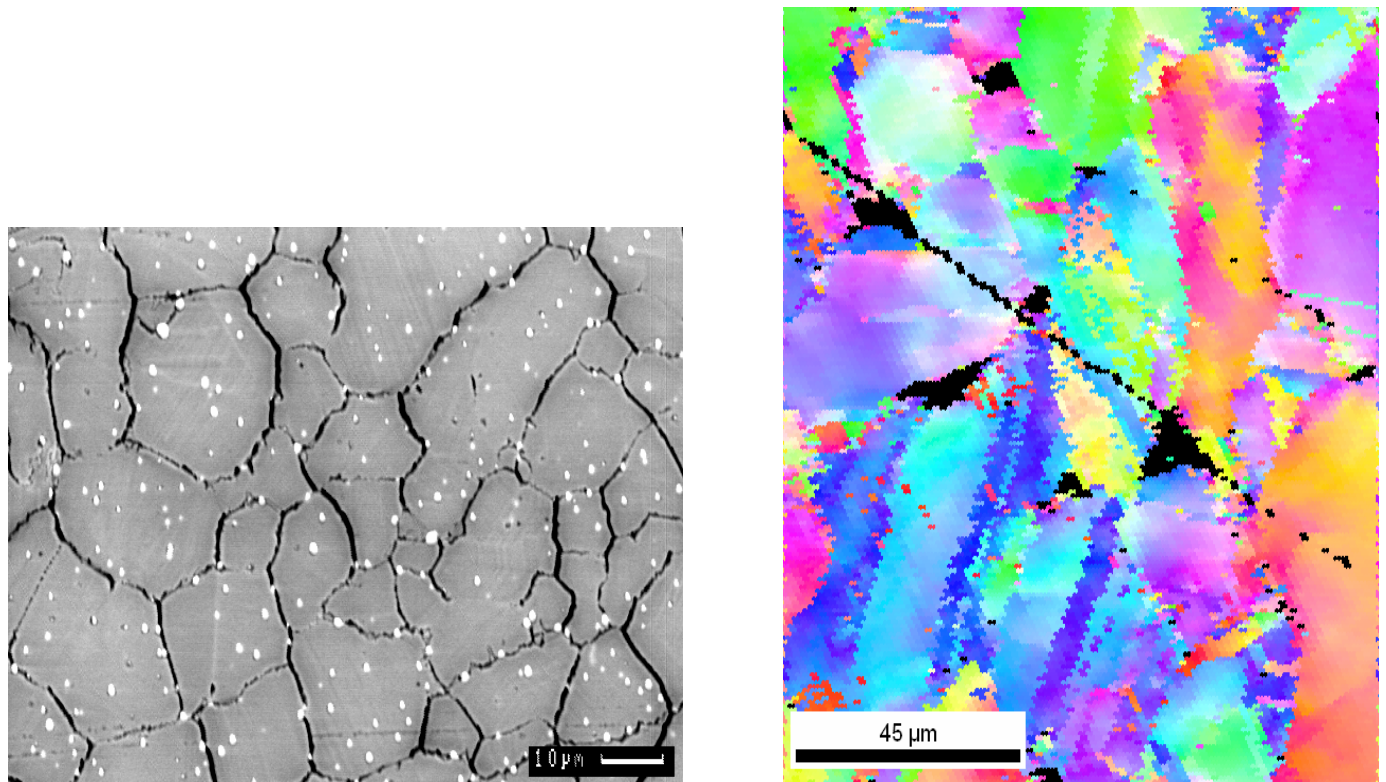

FIG. 2. (a) BSE SEM image of a $25 \%$ cold rolled sample that was tested in-situ at $650^{\circ} \mathrm{C}$ and $300 \mathrm{MPa}$ and (b) a EBSD map of a $25 \%$ cold rolled sample that had undergone a creep rupture experiment at $815^{\circ} \mathrm{C}$ and $165 \mathrm{MPa}$ and exhibited over $20 \%$ strain to failure. These images show the susceptibility to grain boundary cracking for the alloy during creep.

\section{References}

[1] Hayes 188 Alloy Bulletin, Hayes International. H-3001B (2000) 1.

[2] T. Watanabe, Res Mechanica. 11 (1984) 47.

[3] This work was supported by the National Science Foundation through grant DMR-0533954. The authors are grateful to Mr. Nate Eisinger of Special Metals Corporation for performing the thermomechanical processing. 